\title{
SIDA: una travesía desde la impotente desesperanza al éxito terapéutico
}

Prof. Dr. Marcelo Wolff Reyes, FACP, FIDSA

AIDS: a travel since impotent despair to the therapeutic success

E ste trabajo es una versión editada de la conferencia de ingreso como Miembro de Número de la Academia Chilena de Medicina del Instituto de Chile el 9 de septiembre de 2014 y su destino original es ser publicado en el boletín de dicha academia. La Academia Chilena de Medicina ha autorizado una publicación adicional en un medio nacional

La infección por virus de inmunodeficiencia adquirida (VIH) es una pandemia que ya abarca 33 años como fenómeno de importancia epidemiológica global. Esta presentación tiene por objetivo entregar una visión muy personal y vivencial de la epidemia desde su aparición en el mundo occidental hasta mediados de 2014 con un formato de línea del tiempo de los hitos más importantes -a juicio del autor- a nivel global, nacional e, incluso, personal, pues la mayor parte del desempeño profesional del autor ha tenido relación temporal, geográfica, laboral y académica con la patología desde su inicio. Por esta razón la visión seguramente tendrá sesgos, errores, falencias y posiblemente desequilibrios de los que el autor se hace responsable.

Habiendo llegado a los 33 años de la epidemia, ¿Cómo hemos llegado hasta aquí? La respuesta a esa pregunta es la meta de esta presentación.

En el mundo occidental, y particularmente en las ciudades de Nueva York, Los Ángeles y San Francisco de Estados Unidos de América (E.U.A.) empiezan a verse desde fines de la década de los 70 casos de pacientes con infecciones oportunistas de rara ocurrencia fuera del ambiente oncológico, de trasplantes y de inmunosupresiones congénitas o iatrogénicas (i.e corticosteroides) al igual que sarcoma de Kaposi, de rara ocurrencia en hombres jóvenes, sin que esto llevara a un alerta especial fuera de pequeños grupos de especialistas y sus residentes (el autor en esta última categoría, entre 1980-2). En 1981 se notifica, de estas zonas precisamente, tanto en Morbidity and Mortality Weekly Report del entonces llamado Center for Disease Control (CDC) ${ }^{1}$ como en New England Journal of Medicine ${ }^{2}$ la aparición de brotes de neumonía por Pneumocystis carinii (actualmente jirovecii), (PCP) asociadas a inmunodepresión celular severa y candidiasis oral en varones homosexuales. Prontamente se reporta por el CDC brotes de sarcoma de Kaposi (SK) en esa población ${ }^{3}$. Decenas de médicos, instados por el CDC, comienzan a notificar similares casos, dándose cuenta que lo que estaban viendo era realmente un fenómeno nuevo y singular, estableciéndose las principales características de lo que aún no tenía etiología establecida ni nombre específico y que con el tiempo afectaría a millones de personas. Es interesante señalar que antes de estos reportes, una situación particular también evidenció el inhabitual fenómeno: Sandra Ford, una funcionaria administrativa del CDC a cargo de la entrega de medicamentos especiales centralizados desde esa institución notifica el 28 de abril a sus superiores el brusco incremento en las solicitudes de pentamidina, fármaco de segunda elección para $\mathrm{PCP}$, con muy ocasional uso previo. $\mathrm{Al}$ año siguiente el $\mathrm{CDC}$ acuña el término de Síndrome de Inmunodeficiencia Adquirida (AIDS en inglés, SIDA en español) ${ }^{4}$ para referirse al conjunto de patologías infecciosas o tumorales de tipo oportunistas asociadas a moderada o grave inmunodepresión celular sin otra causa razonable y que correspondía al nuevo fenómeno. Esta descripción sindromática ayudó al diagnóstico, en ausencia de una etiología conocida y otros métodos diagnósticos precisos de la causa de esta inmunodepresión y las complicaciones asociadas. Claramente se trataba de la punta del témpano, de los casos más avanzados.

Prontamente se aprecia que hay otros grupos donde la enfermedad aparece: receptores de hemoderivados, usuarios de drogas endovenosas e hijos de madres con la afección. La reacción de la sociedad es ambigua y compleja, apareciendo el temor, la discriminación, la estigmatización, el rechazo e incluso, la justificación moral. A nivel gubernamental hay inicialmente negación, indiferencia y falta de compromiso político para enfrentarlo, sin apoyo a la investigación del problema. Los equipos médicos a cargo, a pesar de la falta de apoyo y reticencia de otros profesionales enfrentan el desafío mayúsculo que se les presentaba y definen en poco tiempo el perfil clínico de la epidemia, y optimizan el manejo y prevención de las complicaciones, lo que, sin embargo, no ayuda a prolongar significativamente la sobrevida de los pacientes.

El carácter epidémico, la clara transmisibilidad por vía sexual y por transfusiones de derivados sanguíneos o uso compartido de jeringas con drogas apuntaban claramente
Facultad de Medicina, Universidad de Chile. Servicio de Medicina Unidad de Infectología Hospital San Borja Arriarán Fundación Arriarán Clínica Santa María

Correspondencia a: Marcelo Wolff Reyes marcewolff@yahoo.com 
a un patógeno transmisible por lo que era esperable el gran hito que llegaría en 1983 con la descripción de un retrovirus específico en los ganglios de una persona con SIDA en el Instituto Pasteur de Francia y que denominaron Virus Asociado a Linfadenopatía (LAV en inglés) ${ }^{5}$. Concomitantemente en E.U.A. se describe un virus similar (que resultaría idéntico a LAV) asociado a la enfermedad y que fue denominado HTLV-III (en inglés Human T Lymphotropic Virus III) ${ }^{6}$, generando, además de la aclamación por el tremendo hallazgo científico, cierta controversia sobre la verdadera autoría del hallazgo (En 2008 Francoise Barré Sinoussi y Luc Montagnier, del Instituto Pasteur, recibirían el Premio Nobel por esta contribución científica).

Ese año se funda en el país la Sociedad Chilena de Infectología, conjunción de microbiólogos clínicos, especialistas nacionales en enfermedades infecto-contagiosas, infectólogos modernos derivados de la medicina interna e infectólogos pediátricos, siendo su primer presidente el Profesor Mario Salcedo. Esta sociedad jugaría desde su creación un rol trascendente en las patologías infecciosas en general y la epidemia de SIDA en particular en el país, donde en 1984 se reporta el primer caso de SIDA. Su aparición genera las mismas reacciones encontradas que en otros sitios, y destacan reacciones irracionales como la quema de los insumos médicos usados en un paciente, la quema de la modesta vivienda de otro luego de su fallecimiento o la solicitud a un afectado del retiro de sus hijos del exclusivo colegio a que asistían.

En 1985 se produce un segundo hito importante a nivel global al aprobarse el primer test serológico para detectar la infección por el aún llamado LAV/HTLV-III, permitiendo diagnosticarla, además de en los enfermos de SIDA, en miles de personas asintomáticas y con nulo o mínimo compromiso inmune, los "portadores", que correspondían tan sólo a infectados en las fases iniciales de la enfermedad. Muy importantemente, entregó una herramienta a los bancos de sangre para eliminar selectivamente la sangre contaminada con el virus y hacer de las transfusiones una práctica segura en ese ámbito; la donación de órganos también se beneficiaría por la misma razón. Al año siguiente se resuelve la disputa del nombre del virus en negociaciones al más alto nivel entre los presidentes de Francia, Francois Mitterand, y E.U.A., Ronald Reagan, con todo lo que implicaba en patentes comerciales. El virus pasa a llamarse Virus de Inmunodeficiencia Humana (HIV en inglés, VIH en español). En el país se establece el primer policlínico de VIH/SIDA en el entonces denominado Hospital Paula Jaraquemada (que funcionaría en la oficina de salud del personal sin mayores problemas).

En 1987 la Agencia Federal de Medicamentos y Alimentos de E.U.A., (Food and Drug AdministrationFDA), aprueba el uso del primer medicamento con acción anti-retroviral, zidovudina o AZT, fármaco que a pesar de tener eficacia moderada y efecto temporal ${ }^{7}$ jugaría un rol fundamental en el arsenal terapéutico anti VIH por cerca de los siguientes 30 años, También se desarrollan técnicas de confirmación de la infección (Western Blot) detectada por examen de tamizaje por otras técnicas menos específicas, reduciendo el problema de estudios con resultado indeterminados y falsos positivos. En Chile se empieza el tamizaje obligatorio en los bancos de sangre y en donantes de órganos, lo que se asocia prácticamente a la desaparición de los casos por transfusiones, con lo que la inmensa mayoría de los casos serían de transmisión sexual, con un pequeño porcentaje de trasmisión vertical y aún más pequeña, por drogadicción endovenosa. Se reconocen los primeros casos de infección del personal de salud a través de accidentes corto punzantes con infectados, lo que no ayuda a aminorar la reticencia de mucho para atender a estos pacientes.

En 1988 la Organización Mundial de la Salud (OMS), entidad internacional a cargo del manejo de la epidemia, declara $a l 1^{\circ}$ de diciembre como el Día Mundial del SIDA.

En 1990 se reconoce el potencial de contagio a pacientes por parte de personal de salud infectado siendo el más destacado el de varios pacientes desde un odontólogo infectado ${ }^{8}$. Afortunadamente, hasta ahora sólo se ha descrito otro caso similar. En el país se crea la Comisión Nacional de SIDA ministerial, CONASIDA, a cargo de los programas de prevención y manejo de la epidemia, y que funcionaría con ese nombre por 20 años.

En 1991 se aprueba una segundo fármaco antiretroviral, didanosina y se describe el potencial de uso combinado de estos medicamentos. Se estima en 10 millones las personas infectadas. En el país se inaugura el Centro de Atención Integral de Enfermedad por VIH y de Capacitación del Personal de Salud: Fundación Arriarán, la que luego de reparar y rehabilitar un edificio abandonado al interior del ahora llamado Hospital San Borja Arriarán inicia su quehacer con 80 pacientes (Figura 1); se establecen en sus dependencias, entregadas en comodato, la Unidad de Infectología de adultos y se inicia el programa de formación de infectólogos de la Facultad de Medicina de la Universidad de Chile, primer programa oficial del país. A mediados de 2014 el centro, el mayor del país, llegaría a tener 3.200 pacientes activos, y se habrían formado 30 especialistas.

Al año siguiente, se reporta que el SIDA ya es la primera causa de muerte entre varones de 25-45 años en E.U.A. En 1993 el CDC reclasifica las condiciones definitorias de SIDA incluyendo a la tuberculosis, el cáncer cérvico-uterino, las neumonías a repetición y el recuento de linfocitos T CD4 $<200$ céls. $x$ mm $^{39}$. A nivel nacional se empieza la distribución restringida de zidovudina como monoterapia en el sistema público de salud, y se da comienzo a las campañas ministeriales de prevención de 
la infección, con énfasis en la fidelidad y la abstinencia; la palabra "condón" queda fuera de los mensajes y se usa la expresión "barrera mecánica".

En 1994 se aprueban nuevos anti-retrovirales y se documenta la eficacia del uso de zidovudina para prevenir la transmisión vertical con $66 \%$ de reducción de infecciones en el recién nacido ${ }^{10}$. Un nuevo hito ocurre en 1995 cuando David Ho (Hombre del Año para la revista Time en 1996) describe la dinámica viral y los reservorios latentes ${ }^{11}$ : no hay estado de reposo, hay masiva y constante replicación viral y destrucción de linfocitos $\mathrm{T}$ CD4+, cuya producción constante logra mantener su número temporalmente. Paralelamente se aprueba el primer antiretroviral de la familia de los inhibidores de proteasa (saquinavir), que usado en conjunto con otros fármacos previamente aprobados, logra marcada reducción de la replicación viral (indectabilidad plasmática) sostenida: nace el concepto de Terapia Antirretroviral Altamente Activa (HAART, Highly Active Antiretroviral Therapy en inglés), que cambiaría el curso de la enfermedad, de una rápida y uniformemente letal a una crónica de larga sobrevida, pero a su vez, pone de manifiesto que debido a los reservorios la infección es inerradicable con este enfoque farmacológico.

Dada la magnitud de la pandemia, el programa global de lucha contra el SIDA pasa a ser administrado directamente por las Naciones Unidas (ONU), naciendo el ONUSIDA. En el país se publica la primera caracterización del perfil clínico epidemiológico de la epidemia ${ }^{12}$ y se oficializa la creación de centros de atención VIH en todos los servicios de salud nacionales. Al año siguiente, 1996, se inician programas de aplicación masiva de terapia moderna en países industrializados, se aprueba un medicamento de la tercera familia de anti-retrovirales, los inhibidores no nucleósicos de transcriptasa reversa, nevirapina y, además, el examen de cuantificación del virus en sangre, la carga viral, pasando a contarse con la primera herramienta objetiva y cuantitativa que permite monitorear la supresión de la replicación viral en el compartimento sanguíneo. En Chile, se amplía el acceso a terapia combinada doble, ya documentada como subestandar, pero aún con cobertura muy incompleta, lo que establece grandes problemas éticos para la selección entre personas igualmente necesitadas, de a quién otorgársela. Los centros, sin una guía clara, definen localmente la modalidad, llegando incluso al sorteo, siendo todas las alternativas muy insatisfactorias e insuficientes. Se documenta en los países que implementan el acceso a terapia óptima, una dramática disminución de la mortalidad ${ }^{13}$, la que contrasta fuertemente con el tremendo y persistente aumento de la epidemia y consecuente mortalidad en África, quedando de manifiesto la gran desigualdad de recursos y oportunidades.

En 1998 fallece en accidente aéreo Jonathan Mann, di- rector de ONUSIDA, luchador infatigable por promover la prevención y tratamiento del SIDA en esos lugares y disminuir esa desigualdad. En el país la Sociedad Chilena de Infectología constituye el Comité Consultivo de SIDA, el que elabora dos pronunciamientos, uno sobre los requisitos técnicos y éticos para la realización del examen de pesquisa ${ }^{14}$ y otro que advierte sobre la insuficiente efectividad y cobertura del programa nacional, instando a implementar un programa moderno más efectivo y con cobertura completa ${ }^{15}$. Se crea la asociación de Personas Viviendo con VIH: VivoPositivo.

En 1999 se documenta la efectividad de la monodosis de nevirapina durante el periparto para disminuir la transmisión vertical en 50\%, lo que se empieza a aplicar en África ${ }^{16}$, a pesar de lo cual la expectativa de vida en la región se reduce de 59 a 45 años. Con el inicio del nuevo siglo se asiste a la explosión epidémica del SIDA en la ex Unión Soviética y varios países de Europa del Este, empujado principalmente por las alteraciones socio económicas derivadas del cambio político de la época en la región y la expansión de la drogadicción endovenosa. También aparece con fuerza en India y Asia, estimándose en 22 millones las personas ya fallecidas por la epidemia. La Declaración de Durham, firmada por miles de científicos y profesionales sanitarios exige acceso universal a terapia. Este llamado es recibido en el país, que incorpora la terapia anti-retroviral moderna al programa. Una enfermera de Fundación Arriarán es diagnosticada con tuberculosis pulmonar, estimada de adquisición por contacto laboral.

En 2001, India empieza a producir anti-retrovirales

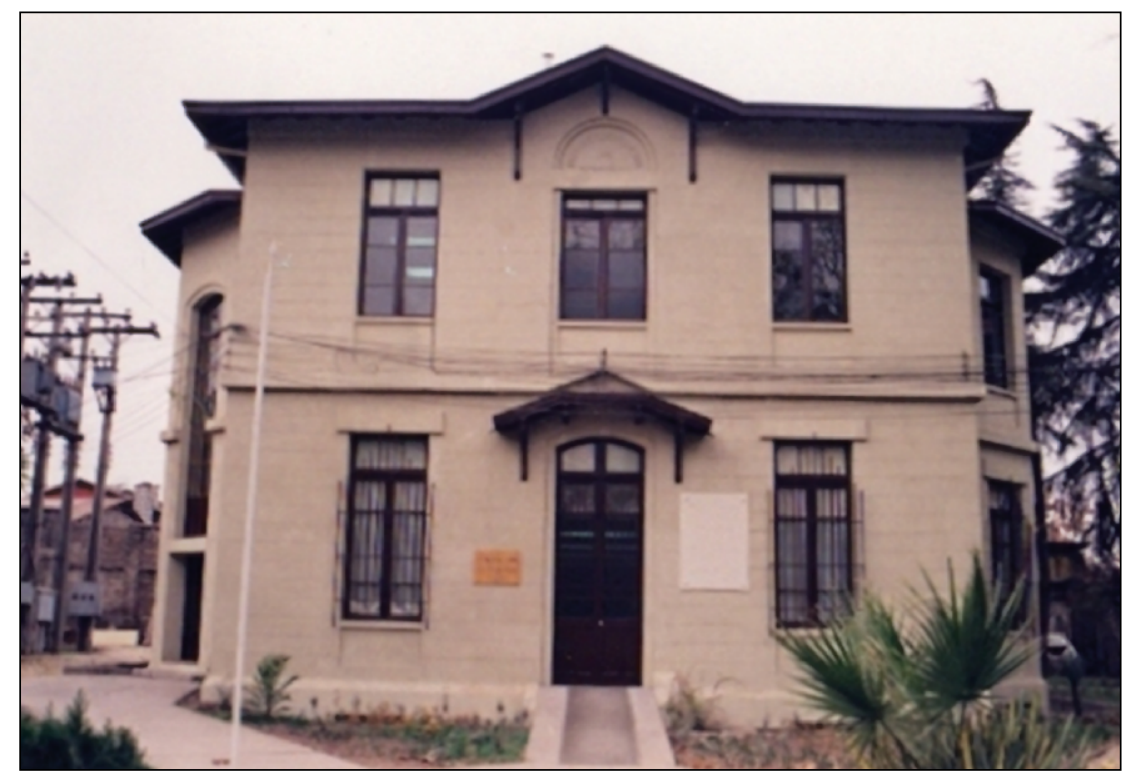

Figura 1. Edificio de la Fundación Arriarán, al momento de su inauguración en el recinto del Hospital San Borja Arriarán, en 1991. 
genéricos con la meta de un costo de 1 dólar estadounidense diario. Se desarrolla la prueba de genotipificación del VIH, técnica que permite detectar las mutaciones asociadas a resistencia a anti-retrovirales específicos. Este verdadero "antivirograma" permitiría desde entonces seleccionar los fármacos posibles de ser activos luego de fracasos terapéuticos. Localmente aparece la primera guía terapéutica nacional patrocinada por el MINSAL.

$\mathrm{Al}$ año siguiente se lanza el programa Fondo Global para la Lucha contra el SIDA, la tuberculosis y la malaria (FG) con el patrocinio de ONUSIDA y que recibe donaciones diversas, entre las que destaca las de Bill y Melinda Gates y en 2003 se lanza el programa “ $3 \times 5$ " con la meta de llegar a 3 millones de personas en tratamiento para el año 2005 en países con recursos limitados (no alcanzaría su objetivo). En E.U.A., se inicia el que sería el exitoso programa PEPFAR (Programa Presidencial de Emergencia para el Alivio del SIDA) por el gobierno de George Bush para apoyar la expansión de tratamiento en regiones sin recursos para financiarlo. Se reporta la ineficacia del primer gran ensayo con una vacuna (AIDS$\mathrm{VAX}^{\mathrm{TM}}$ ). En Chile, con contribución del FG, se logra financiamiento de $100 \%$ en el sistema público, luego el programa se desarrollaría sólo con recursos locales. Precisamente en ese momento se constituye el Grupo SIDA Chile que reúne a casi todos los centros tratantes del país para hacer seguimiento homogéneo de los pacientes y evaluar el impacto del programa ministerial; los pacientes participantes ( $>95 \%$ de los tratados) pasan a constituir la Cohorte Chilena de SIDA, que aportaría con los años información científica relevante e influiría enormemente en las guías nacionales. Se reconoce el potencial sinérgico de la Reforma Sanitaria, el programa de acceso ampliado a terapia y la cohorte nacional ${ }^{17}$.

En 2005 se reporta que la circuncisión masculina disminuye el contagio en hombres heterosexuales en 50$60 \%{ }^{18}$; se implementa a nivel nacional esta reforma sanitaria; la infección por VIH es incluida entre las patologías con garantía de prestaciones, oportunidad de tratamiento y protección financiera. Las ISAPRES (Instituciones de Salud Previsional) pasan a tener la obligación de otorgar terapia a sus afiliados, con el beneficio colateral del término del mercado negro de anti-retrovirales del sector público al privado. El MINSAL establece estándares para la infraestructura de los centros de atención, el personal de salud y su capacitación así como los estándares de atención mismos, los que se establece que en algún momento se harían obligatorios (aún no ocurre). La cohorte nacional obtiene su primera publicación internacional ${ }^{19}$. Al año siguiente Fundación Arriarán publica que la mortalidad anual de su población en control ha disminuido desde $16 \%$ entre la era pre HAART a $1,6 \%$ en la post HAART $^{20}$, (posteriormente se estabilizaría en alrededor de $1 \%$ ). Un cálculo comparativo entre el impacto de diversas intervenciones en patologías graves sitúa a la terapia anti-retroviral en primer lugar con 160 meses de vida adicionales ganados ${ }^{21}$.

Para 2007, ONUSIDA advierte que sólo $28 \%$ de la población mundial que lo necesita está en tratamiento y se reporta que un segundo ensayo con vacuna no muestra beneficio protector.

En 2009 se publica el caso de un paciente infectado con VIH quien luego de un trasplante de precursores hematopoyéticos por linfoma logra mantenerse con carga viral indetectable en ausencia de terapia, por largo tiempo; estudios en sus reservorios no detectan precursores génicos del virus y se produce recuperación inmunológica ${ }^{22}$. Lo más interesante es que el donante, además de gran histocompatibilidad con el receptor, era homocigoto para la mutación que determina ausencia del co-receptor celular de VIH (CCR5) -situación presente en $<$ del 1\% de la población- lo que impide la penetración del virus a las células blanco. Este paciente, que se mantiene en este estado en estudios posteriores, constituye el llamado "Paciente de Berlín" y finalmente se considera el primer curado de la infección por VIH (además del linfoma). Nace la posibilidad de erradicar el virus.

En 2010 se publica la experiencia de la cohorte nacional en tratamiento a largo plazo, con resultados similares a los de países industrializados ${ }^{23}$; la recomendación de inicio de terapia en estados más precoces llega a las guías nacionales. En 2011 se produce un nuevo hito en el control de la epidemia, M. Cohen y cols. presentan evidencia que muestra que en parejas estables serodiscordantes, con sólo un miembro infectado y sin inmunodepresión, la terapia precoz de éste (en niveles aún no indicados en la mayoría de las guías) tiene una eficacia preventiva de $>90 \%$ en el no infectado en comparación con el inicio retardado hasta llegar a mayor nivel de inmunodepresión, de acuerdo al estándar terapéutico del momento ${ }^{24}$, con lo que la terapia precoz pasa a ser considerada como una herramienta preventiva de importancia epidemiológica y la balanza se inclina a tratamiento cada vez más precoz (la revista Science elige a este estudio y su publicación como el hito científico de mayor impacto en 2011). En Chile CONASIDA deja de ser una unidad específica, pero el programa se mantiene. Al año siguiente la FDA aprueba, sin acuerdo unánime, el uso de una combinación anti-retroviral (tenofovir/emtricitabina) como medida preventiva pre-exposición, en personas no infectadas con riesgo de exposición al virus. No se acompañó de recomendaciones más específicas o de clarificación del responsable financiero de la medicación, por lo que su aplicación sigue siendo muy limitada.

En 2013 las dos guías terapéuticas más importantes de E.U.A. la gubernamental del Departamento de Salud y Servicios Humanos (DHHS) y la rama estadounidense de la International AIDS Society (IAS-USA) asumen la 
posición de recomendar inicio de tratamiento en a todos los infectados apenas sean diagnosticados, la llamada estrategia TNT (Test aNd Treat, testear y tratar). La OMS adopta la recomendación de inicio de tratamiento más precoz $\left(\mathrm{CD} 4<500 \times \mathrm{mm}^{3}\right)^{25}$, pero no respalda la posición estadounidense. Chile adopta la recomendación OMS. Los intentos de cura se multiplican y se reportan dos casos de pacientes infectados, con enfermedad tumoral, heterocigotos para la mutación de ausencia de co-receptor CCR5 que reciben trasplante de precursores hematopoyéticos y que se mantienen por meses indetectables sin terapia pero con presencia de precursores génicos del virus en reservorios ${ }^{26}$. Y luego el de un recién nacido de madre infectada sin tratamiento que ingresa en trabajo de parto y no se aplica protocolo de prevención. Por el alto riesgo de infección se inicia terapia en el niño a las pocas horas de nacido y se documenta infección precozmente; obteniéndose indetectabilidad viral. La madre posteriormente suspende la terapia pero el niño se mantiene indetectable por meses ${ }^{27}$. Se acuña el concepto de "cura funcional" o control del virus sin terapia por tratamiento intensivo inicial sin documentar erradicación viral. Este concepto tendría escasa vida al reportarse posteriormente la recaída virológica de todos estos casos. A nivel nacional se produce la inesperada situación de un paciente infectado con linfoma leucemizado que al requerir trasplante de precursores hematopoyéticos, una joven miembro del equipo tratante plantea estudiar el estado de los co-receptores del donante, quien resulta ser homocigoto al igual que con el "paciente de Berlín". Es trasplantado, y se mantiene la terapia, la médula se recupera, pero a los 4 meses fallece bruscamente de neumonía fulminante (meses más tarde se informaría, desde centros especializados, que las muestras post trasplante enviadas para estudio no detectaron material génico proviral...). Los médicos involucrados en estos casos de trasplantes destacan la alta mortalidad peritrasplante de otros casos similares ya sea por infecciones o por enfermedad de injerto versus huésped (T. Henrich, comunicación personal) por lo que se confirma el mínimo potencia de este enfoque. La cura farmacológica, sin activación y destrucción de los reservorios se considera altamente improbable y lejana.

Se llega a 2014 y se estima que en el país habría entre 50 mil a 70 mil infectados $(0,3-0,4 \%$ de la población mayor de 15 años, pero con gran preponderancia masculina), con menos de la mitad diagnosticados, 22 mil en control, alrededor de 18.500 en el sistema público, cerca de $90 \%$ de ellos en tratamiento $\mathrm{y} 3 / 4$ de los pacientes en terapia estable con indetectabilidad viral, y una reducción de mortalidad mayor a $80 \%$. La mortalidad a 3 años se ha visto reducida de $20,8 \%$ en el período $2001-2003$ a 3,4\% entre 2008-2010 (Datos no publicados de la Cohorte Chilena de SIDA). Estos favorables resultados pueden ser engañadores pues se obtiene en la minoría que está bajo

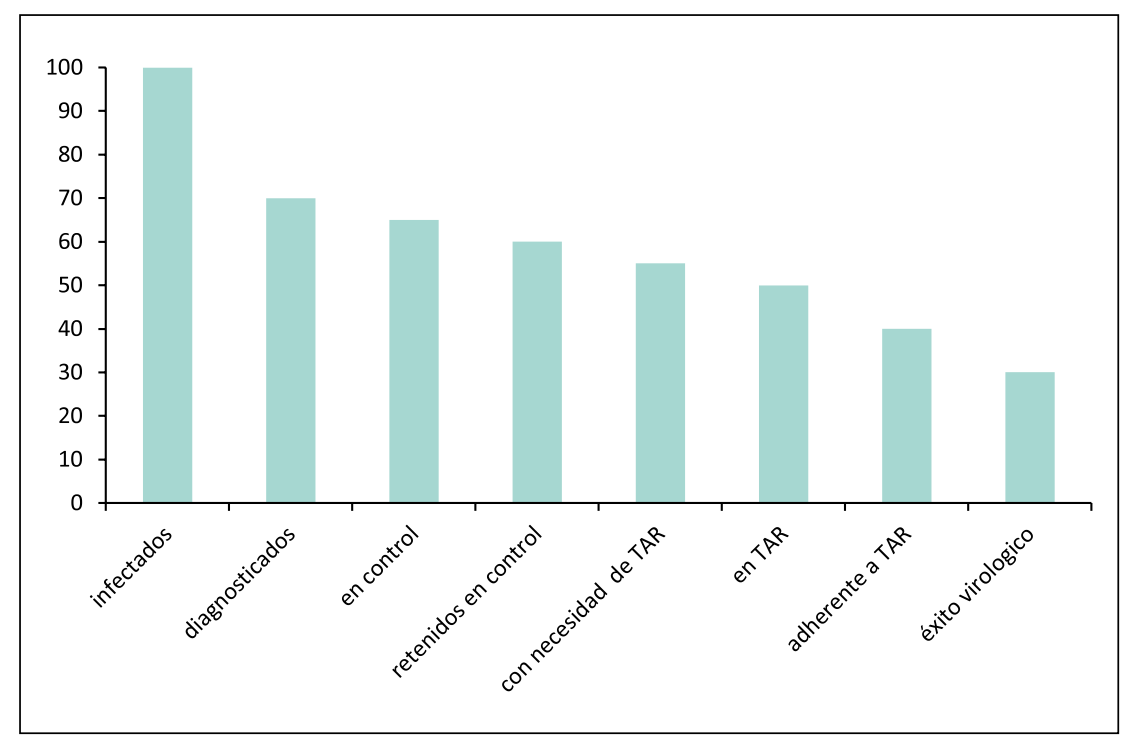

Figura 2. Cascada de atención VIH. Distribución porcentual de las distintas fases del proceso. Los porcentajes en cada fase varían por regiones y centros. TAR: terapia antiretroviral.

control y con adherencia a su tratamiento. Al analizar las diferentes fases del proceso total de manejo de la enfermedad, graficado con lo que se ha denominado la "Cascada en la Atención VIH" se reconocen poblaciones de tamaño decreciente que se inician con: 1) infectados; 2) diagnosticados; 3 ) en control; 4) retenidos en control; 5) con necesidad de terapia; 6) bajo terapia; 7) adherente a terapia y; 8) con éxito virológico (Figura 2).

El último grupo es una proporción variable del primero pero fue estimada en 2010 en $25 \%$ en E.U.A. ${ }^{28}$. Esta caracterización de la cascada de atención, compartida con otras patologías crónicas, permite identificar y cuantificar las brechas y planificar soluciones para minimizarlas. Claramente en el mundo, y en Chile en particular, el principal problema es el diagnóstico tardío y una retardada derivación o postergada decisión personal de consulta, como lo refleja la experiencia de Fundación Arriarán, donde aún ahora $80 \%$ de los pacientes ingresa con diagnóstico tardío (CD4 < a 350 céls. $x$ mm $^{3}$ ) o enfermedad avanzada

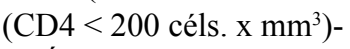

Ésta ha sido una larga travesía (recientemente se habría documentado que el virus inició su expansión originalmente en Kinshasa, actual República Democrática del Congo, en $1922^{29}$ ) durante la cual ha habido un gran impacto humano: > 60 millones de infectados, 30 millones de fallecidos y cerca de 35 millones vivos con la enfermedad. La cobertura terapéutica sigue creciendo y se ha demostrado que en países con severas limitaciones de recursos se puede aplicar el programa masivo de tratamiento con éxito, pero aún no se llega a la mitad de los infectados. El lema de la Conferencia de SIDA 
Tabla 1. Evolución cronológica de hitos en la pandemia de VIH a nivel mundial, nacional y local

\begin{tabular}{|c|c|c|c|}
\hline Año & Global/Mundial & Nacional & Local \\
\hline 1978-1980 & EEUU, casos aislados, no reconocibles como entidad específica & & \\
\hline 1981 & $\begin{array}{l}\text { Reporte MMWR, NEJM: PCP, SK } \\
\text { S Ford, CDC, reporta incremento en uso de pentamidina }\end{array}$ & & \\
\hline 1982 & $\begin{array}{l}\text { CDC acuña término Sindrome de Inmunodeficiencia Adquirida (AIDS } \\
=\text { SIDA) }\end{array}$ & & \\
\hline 1983 & Instituto Pasteur describe LAV y NIH HTV-III & Se funda la Sociedad Chilena de Infectología & \\
\hline 1984 & & Primer caso nacional & \\
\hline 1985 & $\begin{array}{l}\text { Test diagnóstico para la infección } \\
\text { "Portadores asintomáticos" } \\
\text { Inicio de suministro seguro de sangre }\end{array}$ & & \\
\hline 1986 & LAV/HTLVIII pasa a denominarse VIH & & $\begin{array}{l}\text { Se crea policlínico VIH en Hosp. P. Jara- } \\
\text { quemada }\end{array}$ \\
\hline 1987 & $\begin{array}{l}\text { Se aprueba zidovudina (AZT) } \\
\text { Test de confirmación (Western Blot) } \\
\text { Infecciones por accidente ocupacional }\end{array}$ & Tamizaje obligatorio bancos de sangre & \\
\hline 1988 & $\begin{array}{l}1^{\circ} \text { de Diciembre } \\
\text { Día Mundial del SIDA } \\
\text { Lazo rojo como símbolo }\end{array}$ & & \\
\hline 1989 & 100.000 casos EEUU & & \\
\hline 1990 & $1^{\text {a }}$ transmisión de personal de salud infectado a pacientes & Se crea CONASIDA & \\
\hline 1991 & Se aprueba didanosina & & $\begin{array}{l}\text { Se inaugura Fundación Arriarán: } 80 \text { pacien- } \\
\text { tes (2014: 3200) }\end{array}$ \\
\hline 1992 & $\begin{array}{l}\text { SIDA: primera causa de muerte hombres } 25-45 \text { años, EEUU } \\
\text { África asolada por SIDA }\end{array}$ & & \\
\hline 1993 & Re-etapificación de infección por VIH por CDC & Se inicia distribución limitada de zidovudina & \\
\hline 1994 & $\begin{array}{l}\text { Se aprueba estavudina } \\
\text { AZT disminuye en } 66 \% \text { transmisión vertical (TV) }\end{array}$ & & \\
\hline 1995 & $\begin{array}{l}\text { D. Ho describe la activa dinámica viral: no hay latencia ni reposo } \\
\text { Se aprueba inhibidor de proteasa } \\
\text { Nace concepto HAART } \\
\text { Se crea ONUSIDA }\end{array}$ & $\begin{array}{l}\text { Se crean los centros de atención en todos } \\
\text { los servicios del país }\end{array}$ & $\begin{array}{l}\text { Grupo publica primer perfil clínico epide- } \\
\text { miológico nacional }\end{array}$ \\
\hline 1996 & $\begin{array}{l}\text { Test de carga viral } \\
\text { Se aprueba nevirapina (INNTR) }\end{array}$ & $\begin{array}{l}\text { Se inicia biterapia en Chile: cobertura incom- } \\
\text { pleta, eficacia parcial }\end{array}$ & \\
\hline 1997 & Cae mortalidad a la mitad con el tratamiento, EEUU & & \\
\hline 1998 & $\begin{array}{l}\text { Muere Jonathan Mann } \\
\text { Director ONUSIDA }\end{array}$ & $\begin{array}{l}\text { Se crea el Comité consultivo de SIDA } \\
2 \text { pronunciamientos } \\
\text { Se crea VivoPositivo }\end{array}$ & \\
\hline 1999 & $\begin{array}{l}\text { Expectativa de vida en África cae de } 59 \text { a } 45 \text { años } \\
\text { Monodosis de nevirapina reduce TV en } 50 \%\end{array}$ & & $\begin{array}{l}\text { Se inician ensayos clínicos cooperativos } \\
\text { internacionales }\end{array}$ \\
\hline 2000 & Explota la epidemia en ex Unión Soviética, Europa del Este y Asia & $\begin{array}{l}\text { Se inicia terapia moderna combinada (tri- } \\
\text { terapia) }\end{array}$ & \\
\hline 2001 & $\begin{array}{l}\text { Se producen medicamentos genéricos: India } \\
\text { Se desarrolla test de genotipo }\end{array}$ & Primera guía de terapia nacional: MINSAL & \\
\hline 2002 & $\begin{array}{l}\text { Se crea al Fondo Global para la Lucha contra SIDA, Tuberculosis y } \\
\text { Malaria }\end{array}$ & & \\
\hline 2003 & $\begin{array}{l}\text { Programa " } 3 \times 5 \text { " } \\
\text { Se infectan } 16.000 \text { y mueren } 8.000 \text { al día } \\
\text { Se crea Programa PEPFAR: EEUU } \\
\text { Primer ensayo de vacuna (AIDSVAX): ineficaz }\end{array}$ & $\begin{array}{l}\text { Se crea Grupo SIDA Chile y Cohorte Chilena } \\
\text { de SIDA } \\
\text { Se llega a } 100 \% \text { de cobertura terapéutica en } \\
\text { sistema público }\end{array}$ & \\
\hline
\end{tabular}




\begin{tabular}{|c|c|c|c|}
\hline Año & Global/Mundial & Nacional & Local \\
\hline 2004 & & $\begin{array}{l}\text { Se describe potencial sinérgico de GES, } \\
\text { programa de acceso ampliado a terapia y } \\
\text { cohorte nacional }\end{array}$ & \\
\hline 2005 & $\begin{array}{l}\text { Programa " } 3 \times 5 \text { " no alcanza objetivo } \\
\text { Circuncisión reduce infección en hombres heterosexuales en } 60 \%\end{array}$ & $\begin{array}{l}\text { GES se aplica a sistema público y privado } \\
\text { Se elaboran estándares de personal, estruc- } \\
\text { tura y atención en los centros VIH }\end{array}$ & $\begin{array}{l}\text { Cohorte Chilena de SIDA obtiene } 1^{\text {a }} \text { publica- } \\
\text { ción internacional }\end{array}$ \\
\hline 2006 & & & $\begin{array}{l}\text { Centro muestra reducción en mortalidad } \\
\text { anual de } 16 \% \text { (1996) a 1,6\% (2006) }\end{array}$ \\
\hline 2007 & $\begin{array}{l}\text { Segundo ensayo con vacuna: ineficaz } \\
\text { Sólo } 28 \% \text { población en tratamiento }\end{array}$ & & \\
\hline 2009 & Primer caso de cura: "El paciente de Berlín" & & \\
\hline 2010 & & $\begin{array}{l}\text { Terremoto no afecta al programa } \\
\text { MINSAL recomienda inicio de tratamiento } \\
\text { más precoz }\end{array}$ & $\begin{array}{l}\text { Segunda publicación internacional de Co- } \\
\text { horte Chilena de SIDA internacional }\end{array}$ \\
\hline 2011 & Estudio HPTN 052: tratamiento como prevención & $\begin{array}{l}\text { Se reorganiza CONASIDA, es absorbido por } \\
\text { otras instancias }\end{array}$ & \\
\hline 2012 & FDA aprueba Truvada ${ }^{\circledR}$ como profilaxis pre exposición (PREP) & & \\
\hline 2013 & $\begin{array}{l}\text { DHHS e IAS-USA: tratamiento a todos ("Estrategia TNT") } \\
\text { OMS con CD } 4<500 \times \mathrm{mm}^{3} \\
\text { "Pacientes de Boston y Bebé de Mississippi" } \\
\text { ¿cura funcional? }\end{array}$ & & Paciente local similar al de Berlín, \\
\hline 2014 & $\begin{array}{l}\text { Pacientes de Boston y Bebe de Mississippi recaen } \\
\text { Fin a cura funcional } \\
\text { Melbourne 2014: "Apurar el paso"; } \\
\text { "Sabemos lo que hay que hacer, completemos el trabajo" }\end{array}$ & $\begin{array}{l}50-70 \text { mil infectados } \\
22000 \text { en control } \\
90 \% \text { en tratamiento }\end{array}$ & $\begin{array}{l}\text { Paciente con trasplante fallece } \\
\text { (ADN proviral sin precursores génicos de } \\
\text { VIH) } \\
\text { Evaluación local de cascada de atención VIH }\end{array}$ \\
\hline
\end{tabular}

2014, sacudida por la trágica, absurda y brutal muerte de otro pionero en la lucha contra el SIDA, Joep Lange, fue "Apurar el paso" pues "Sabemos lo que hay que hacer, completemos el trabajo" (David Cooper, $20^{\circ}$ Conferencia de SIDA, Melbourne, julio, 2014). La Tabla 1 resume los hitos analizados.

Hay un par de reflexiones finales, que el autor se permite hacer: esta enfermedad ha sido un motor enorme de avance científico y tecnológico que ha impulsado grandes avances para la comprensión y manejo de muchas otras enfermedades, y ha llevado por primera vez en la historia a que una misma generación de profesionales de la salud y científicos, la mayoría aún muy vigente, haya sido testigo y actor de su aparición, su caracterización clínica y fisiopatológica, el manejo de sus complicaciones, la aparición de tratamiento específico efectivo para su control y la implementación exitosa de su uso masivo, llevando una enfermedad de alta y rápida letalidad a ser una patología crónica, tratable, de larga sobrevida, con buena calidad de vida y reinserción social, laboral y familiar. Está aún pendiente saber si esta generación verá la cura definitiva o la prevención con vacunas efectivas, aun cuando es claro que serán las nuevas generaciones las que asumirán el rol principal de dirigir esos esfuerzos. No cabe duda que lo lograrán. Para que esa generación que emprende ese camino entienda el presente y se prepare para el futuro debe empezar por conocer el pasado. Esta presentación ha querido aportar en ese sentido.

Agradecimientos: El autor agradece a todos los profesionales y personal técnico administrativo de Fundación Arriarán, a todos los especialistas que se han formado en sus dependencias así como los innumerables estudiantes de pre y postgrado que han asistido a la unidad, por su entrega, compromiso, aporte intelectual y permanente estímulo para aspirar a niveles de excelencia en asistencia, capacitación e investigación. Un reconocimiento especial a los miles de pacientes y sus familiares que nos han distinguido con su confianza poniendo su salud en nuestras manos. 


\section{Referencias bibliográficas}

1.- CDC. Pneumocystis pneumonia-Los Angeles. MMWR Morb Mortal Wkly Rep 1981; 30: 250-2.

2.- Gottlieb M S, Schroff R, Schanker H M, Weisman J D, Fan P T, Wolf R A, et al. Pneumocystis carinii pneumonia and mucosal candidiasis in previously healthy homosexual men. Evidence of a new acquired cellular immunodeficiency. N Engl J Med 1981; 305: 1425-31.

3.- CDC. Kaposi's sarcoma and Pneumocystis pneumonia among homosexual men. New York City and California. MMWR 1981; 30: 305-8.

4.- CDC. Update on acquired immune deficiency syndrome (AIDS)-United States. MMWR 1982; 31: 507-8, 513-4.

5.- Barre-Sinoussi F, Chermann J C, Rey F, Nugeyre M T, Chamaret S, Gruest J, et al. Isolation of a T-lymphotropic retrovirus from a patient at risk for acquired immune deficiency syndrome (AIDS). Science 1983; 220: 868-71.

6.- Gallo R C, Sarin P S, Gelmann E P, Robert-Guroff M, Richardson E, Kalyanaraman V S, et al. Isolation of human T-cell leukemia virus in acquired immune deficiency syndrome (AIDS). Science 1983; 220: 865-7.

7.- Fischl M A, Richman D D, Grieco M H, Gottlieb M S, Volberding P A, Laskin O L, et al. The efficacy of azidothymidine (AZT) in the treatment of patients with AIDS and AIDSrelated complex: a double-blind, placebo-controlled trial. N Engl J Med 1987; 317: 185-91.

8.- CDC. Possible transmission of human immunodeficiency virus to a patient during an invasive dental procedure. MMWR Morb Mortal Wkly Rep 1990; 39: 489-93.

9.- CDC. 1993 Revised classification system for HIV infection and expanded surveillance case definition for AIDS among adolescents and adults. MMWR Morb Mortal Wkly Rep 1992; 41 (RR-17): 1-19.

10.- Connor E M, Sperling R S, Gelber R, Kiselev P, Scott G, O’Sullivan M J, et al. Reduction of maternal-infant transmission of human immunodeficiency virus type 1 with zidovudine treatment. Pediatric AIDS Clinical
Trials Group Protocol 076 Study Group. N Engl J Med 1994; 331: 117380.

11.- Ho D D, Neumann A U, Perelson A S, Chen W, Leonard J M, Markowitz M. Rapid turnover of plasma virions and CD4 lymphocytes in HIV-1 infection. Nature 1995; 373 (6510): 123-6.

12.- Wolff M, Northland R, Segovia J, Beltrán C, Valdés M, Albornoz M, et al. Características clínicas e historia natural de la infección por virus de inmunodeficiencia humana. Rev Med Chile 1995; 123: 61-73.

13.- CDC. Update: trends in AIDS incidence, deaths, and prevalence-United States, 1996. MMWR Morb Mortal Wkly Rep 1997; 46: 165-73.

14.- Comité Consultivo de SIDA de Sociedad Chilena de Infectología. Posición sobre estudios serológicos de la infección por VIH. Rev Chilena Infectol 1998;15: 189-92.

15.- Sociedad Chilena de Infectología, Comité Consultivo de SIDA. Terapia anti retroviral. Rev Med Chile 1998; 126: 577-81.

16.- Guay LA, Musoke P, Fleming T, Bagenda D, Allen M, Nakabiito C, et al. Intrapartum and neonatal single-dose nevirapine compared with zidovudine for prevention of mother-to-child transmission of HIV-1 in Kampala, Uganda: HIVNET 012 randomised trial. Lancet 1999; 354: 795-802.

17.- Wolff M, Beltrán C. Programa de acceso ampliado a terapia antiretroviral, Plan Auge y Cohorte Chilena de SIDA: 3 iniciativas complementarias. Rev Chilena Infectol. 2004; 21: 281-4.

18.- Auvert B, Taljaard D, Lagarde E, Sobngwi-Tambekou J, Sitta R, Puren A. Randomized, controlled intervention trial of male circumcision for reduction of HIV infection risk: The ANRS 1265 Trial. PLoS Med 2005; 2 (11): e298.

19.- Wolff M J, Beltrán C, Vásquez P, Ayala M X, Valenzuela M, Berríos G, et al. and The Chilean AIDS Group.The Chilean AIDS Cohort: a model for evaluating the impact of an expanded access program to antiretroviral therapy in a middle-income country-organization and preliminary results. J Acquir Immune Defic Syndr 2005; 40 (5): 551-7.

20.- Wolff R M, Álvarez P P, Flores S I, Northland A R, Wolff L C. Evolución de mortalidad y estado actual de una población infectada por VIH controlada en un centro multiprofesional. Rev Med Chile 2006, 134: 581-8.

21.- Walensky R P, Paltiel A D, Losina E, Mercincavage L M, Schackman B R, Sax P E, et al. The survival benefits of AIDS treatment in the United States. J Infec Dis 2006; 194: 11-9.

22.- Hütter G, Nowak D, Mossner M, Ganepola S, Müssig A, Allers K, et al. Long-term control of HIV by CCR 5 Ganepola S, Müssig A, Allers K,Delta 32/Delta32 stem-cell transplantation. N Engl J Med 2009; 360: 692-8.

23.- Wolff M J, Cortés C P, Shepherd B E, Beltrán C J; for the Chilean AIDS Cohort Study Group. Long-term outcomes of a National Expanded Access Program to Antiretroviral Therapy: The Chilean AIDS Cohort. J Acquir Immune Defic Syndr 2010; 51: 615-23.

24.- Cohen M S MD, Ying Q, Chen Y Q, McCauley M, Gamble T, Hosseinipour M C, et al, for the HPTN 052 Study Team. Prevention of HIV infection with early antiretroviral therapy. N Engl J Med 2011; 365: 493-505.

25.- World Health Organization. Consolidated guideline on the use of antiretroviral drugs for treating and preventing HIV infection: recommendations for a public health approach. June 2013.

26.- Henrich T J, Hu Z, Li J Z, Sciaranghella G, Busch M P, Keating S M, et al. Long-term reduction in peripheral blood HIV type 1 reservoir following reduced-intensity conditioning allogeinic stem cell transplantation. J Infect Dis 2013; 208 (8): 1189-93.

27- Persaud D, Gay H, Ziemniak C, Chen Y H, Piatak M Jr, Chun T W, et al. Brief Report: absence of detectable HIV-1 viremia after treatment cessation in an infant. $\mathrm{N}$ Eng $\mathrm{J}$ Med 2013; 369: 1828-35.

28.- Gardner E M, McLees M P, Steiner J F. The spectrum of engagement in HIV care and its relevance to test-and-treat strategies for prevention of HIV infection. Clin Infect Dis 2011; 52: 793-800.

29.- Faria N R, Rambaut A, Suchard M A, Baele G, Bedford T, Ward M J, et al. The early spread and epidemic ignition of HIV-1 in human populations. Science 2014; 346: 56-61 